\title{
Propofol protects human cardiac cells against chemical hypoxiainduced injury by regulating the JNK signaling pathways
}

\author{
LIU HAN $^{1,2}$, QIANG ZHUO ${ }^{3}$, YING ZHOU ${ }^{1}$ and YANNING QIAN ${ }^{2}$ \\ ${ }^{1}$ Department of Anesthesiology, Nanjing First Hospital, Nanjing Medical University, Nanjing, Jiangsu 210006; \\ ${ }^{2}$ Department of Anesthesiology, First Affiliated Hospital, Nanjing Medical University, Nanjing, Jiangsu 210029; \\ ${ }^{3}$ Department of Pathology, Xuzhou Medical College, Xuzhou, Jiangsu 221004, P.R. China
}

Received June 7, 2019; Accepted November 7, 2019

DOI: $10.3892 /$ etm. 2020.8440

\begin{abstract}
Propofol is a widely used intravenous anesthetic shown to exert a cardioprotective role against oxidative stress and ischemia/reperfusion injury in rat cardiac $\mathrm{H} 9 \mathrm{c} 2$ cells. However, the regulatory mechanisms and functions of propofol in human cardiomyocytes remain unknown. The present study chemically induced hypoxia with cobalt chloride $\left(\mathrm{CoCl}_{2}\right)$ to mimic cardiomyocyte ischemic injury in human cardiac AC16 and HCM cells. To investigate its underlying mechanisms, propofol was added to the cells before the chemical hypoxia phase. The present results suggested that, in response to hypoxia, mitochondrial membrane potential was lost, and cardiomyocyte viability and superoxide dismutase levels decreased. However, the present results showed that reactive oxygen species and malondialdehyde levels increased. The present results suggested that these effects were significantly reversed following propofol treatment. Additionally, the present results suggested that the protective effect of propofol against $\mathrm{CoCl}_{2}$-induced injury may be inhibited by the activation of the JNK signaling pathways. The present results indicated that propofol pre-treatment inhibited $\mathrm{CoCl}_{2}$-induced myocardial injury by preventing mitochondrial dysfunction, which may be partially due to the activation of the JNK signaling pathways. Therefore, propofol may exert anti-oxidative effects in human cardiac cells. The present results suggested that propofol may be used as a treatment for oxidative stress-related cardiac disorders.
\end{abstract}

Correspondence to: Dr Liu Han, Department of Anesthesiology, Nanjing First Hospital, Nanjing Medical University, 68 Changle Road, Nanjing, Jiangsu 210006, P.R. China

E-mail: han_cold.student@sina.com

Abbreviations: SOD, superoxide dismutase; ROS, reactive oxygen species; MDA, malondialdehyde; CCK-8, Cell Counting Kit-8; $\Delta \psi \mathrm{m}$, mitochondrial membrane potential; PI, propidium iodide; MAPK, mitogen-activated protein kinase

Key words: propofol, cardiomyocyte, hypoxia, apoptosis, JNK, p38

\section{Introduction}

Perioperative acute hypoxic-ischemic cardiac toxicity of anesthetics is one of the most serious complications during surgical procedures, and occurs following the blockade of sodium channels and negative inotropic effect (1-4). To avoid cardiac toxicity, selection of a suitable drug for the maintenance of anesthesia, especially during cardiac surgery, is crucial $(5,6)$. A combination of epidural and general anesthetics have been commonly applied to reduce the use of general anesthetics, such as combining ropivacaine, a local anesthetic, and propofol, a general anesthetic $(7,8)$. Ropivacaine reportedly possesses lower cardiovascular and central nervous toxicity in vivo, in comparison with bupivacaine $(9,10)$. However, its underlying mechanisms remain unknown, and it is unclear whether the mechanism of action is involved in the induction of perioperative ischemic and hypoxic toxicity $(11,12)$.

In contrast, due to its phenolic structure, propofol can prevent ischemic/reperfusion injury $(13,14)$. Furthermore, propofol has an anti-oxidative effect in rat cardiomyocytes and macrophages, which is associated with the suppression of oxidative stress-related enzymes including inducible nitric oxide synthase, superoxide dismutase (SOD) and neutrophil cytosolic factor 1 . In addition, propofol is associated with an increase in intracellular nitric oxide release $(15,16)$ and the preservation of $\mathrm{Bcl} 2$ expression levels (17). Propofol was shown to protect microglia from hypoxia-induced inflammation and apoptosis by maintaining intracellular $\mathrm{Ca}^{2+}$ homeostasis and the activation of the JNK1/Stat3 signaling pathway (18). Furthermore, propofol exerts antiproliferative and anti-invasive effects on hepatocellular carcinoma and rheumatoid arthritis fibroblast-like synoviocytes via the Wnt/ $\beta$ catenin (19) and NF- $\mathrm{NB}$ signaling pathways (20). Previous studies demonstrated that propofol plays a variety of roles in different cell types via various signaling pathways. However, the effects of propofol, especially when combined with ropivacaine, on human cardiomyocytes is not fully understood.

Therefore, the present study used human AC16 and HCM cardiomyocytes treated with cobalt chloride $\left(\mathrm{CoCl}_{2}\right)$ as an in vitro model of cardiomyocyte ischemia. The present study investigated the signaling pathways associated with propofol and/or ropivacaine activity against oxidative stress injury in cardiomyocytes. 


\section{Materials and methods}

Cell culture. Human adult AC16 and HCM cardiomyocytes (21) (cat. nos. BNCC337712 and BNCC337719; Suzhou BeNa Culture Collection Biotechnology Co., Ltd.) were cultured in DMEM/F12 (Thermo Fisher Scientific, Inc.) supplemented with penicillin $100 \mathrm{U} / \mathrm{ml}$, streptomycin $0.1 \mathrm{mg} / \mathrm{ml}$ (Invitrogen; Thermo Fisher Scientific, Inc.) and 10\% FBS (Gibco; Thermo Fisher Scientific, Inc.) at $37^{\circ} \mathrm{C}$ in a $5 \% \mathrm{CO}_{2}$ incubator. To establish hypoxic conditions, the cardiomyocytes were synchronized, incubated in the complete DMEM/F12 with $500 \mu \mathrm{mol} / 1 \mathrm{CoCl}_{2}$ (Sigma-Aldrich; Merck KGaA; CAS Number 7791-13-1), propofol and/or ropivacaine at different concentrations for $12 \mathrm{~h}$ at $37^{\circ} \mathrm{C}$ in a $5 \% \mathrm{CO}_{2}$ incubator.

Cell viability assay. To select the appropriate propofol and ropivacaine concentrations, cell viability was assessed using the Cell Counting Kit-8 (CCK-8; Beyotime Institute of Biotechnology) according to the manufacturer's instruction. Cardiomyocytes were seeded at a density of $3 \times 10^{3}$ cells in 96-well plates in sextuplicate and incubated overnight in the complete DMEM/F12 with or without $500 \mu \mathrm{mol} / 1 \mathrm{CoCl}_{2}$ in an atmosphere with $5 \% \mathrm{CO}_{2}$ at $37^{\circ} \mathrm{C}$. After removing the culture medium, cells were treated with propofol $(100,50,25,12.5,6.25$ and $0 \mu \mathrm{g} / \mathrm{ml})$ or ropivacaine at different concentrations $(300,150,75,37.5,18.75$ and $0 \mu \mathrm{g} / \mathrm{ml}$ in the absence of Cocl2 treatment experiments; 100, 50, 25, 12.5 and $0 \mu \mathrm{g} / \mathrm{ml}$ in the $500 \mu \mathrm{mol} / 1 \mathrm{Cocl} 2$-pretreatment experiments) in fresh medium, repeated eight times, for $48 \mathrm{~h}$ at $37^{\circ} \mathrm{C}$. In addition, to determine the synergistic interactions between propofol and ropivacaine, AC16 and HCM cells were treated by $25 \mu \mathrm{g} / \mathrm{ml}$ of propofol and different ropivacaine concentrations $(200,100$, $50,25,12.5$ and $0 \mu \mathrm{g} / \mathrm{ml}$ ) for $48 \mathrm{~h}$ at $37^{\circ} \mathrm{C}$. The supernatants were discarded and the CCK-8 solution, (dilution, 1:10) was added to each well in complete DMEM/F12, and the cells were incubated for $2 \mathrm{~h}$ at $37^{\circ} \mathrm{C}$. Absorbance at $450 \mathrm{~nm}$ was measured using a microplate reader (cat. no. MQX200; BioTek Instruments, Inc.). All experiments were repeated four times.

Flow cytometry analysis. Cell apoptosis and mitochondrial membrane potential $(\Delta \Psi \mathrm{m})$ were evaluated using flow cytometry analysis. Cardiomyocytes were incubated in complete $\mathrm{DMEM} / \mathrm{F} 12$ with or without $50 \mu \mathrm{g} / \mathrm{ml}$ propofol combined with $50 \mu$ M Juglanin (cat. no. 5041-67-8; HPLC $\geq 98 \%$; Shanghai Zeye Biological Technology Co., Ltd.) for $2 \mathrm{~h}$ at $37^{\circ} \mathrm{C}$, and treated with $500 \mu \mathrm{m} \mathrm{CoCl}{ }_{2}$ in fresh medium for $12 \mathrm{~h}$ at room temperature. Following drug treatments, cells were harvested, washed twice with PBS and stained with Annexin V-FITC/PI Apoptosis Detection kit (cat. no. A211-01; Vazyme Biotech Co., Ltd.) in the binding buffer for $15 \mathrm{~min}$ in the dark at $25^{\circ} \mathrm{C}$ according to the manufacturer's protocol. The fluorescence intensity of Annexin V/PI-stained cells was analyzed using FACSCanto II flow cytometry (Becton, Dickinson and Company) within $1 \mathrm{~h}$. Early apoptotic Annexin $\mathrm{V}^{+} / \mathrm{PI}^{-}$cells were counted using FlowJo software version 7.6.1 (Tree Star, Inc.) and the quadrant percentage was considered to indicate the apoptotic ratio.

To determine the $\Delta \Psi \mathrm{m}$, the remaining harvested cells were incubated with JC-1 staining for $20 \mathrm{~min}$ at $37^{\circ} \mathrm{C}$ according to the manufacturer's protocol of a JC-1 staining kit (cat. no. KGA601; Nanjing Keygene Nanjing Kaiji Biotechnology Co., Ltd.) After washing the samples twice with the incubation buffer in this kit, cells were analyzed using the FACSCanto II flow cytometry (Becton, Dickinson and Company). These experiments were repeated three times.

Reactive oxygen species (ROS) measurements. The effects of propofol on ROS production in $\mathrm{CoCl}_{2}$-treated $\mathrm{AC} 16$ and $\mathrm{HCM}$ cells were determined using a ROS-sensitive fluorescent probe (DCFH-DA) (cat. no. D6883; Sigma-Aldrich; Merck KGaA). Then, cells were analyzed using the FACSCanto II flow cytometry (Becton, Dickinson and Company). The cells were seeded at a density of $2 \times 10^{5}$ cells/well into 6-well plates in triplicate in the following groups: i) Control group, with the cells cultured in complete DMEM/F12; ii) chemical hypoxia group, with the cells cultured in complete DMEM/F12 with $500 \mu \mathrm{mol} / 1 \mathrm{CoCl}_{2}$ for $12 \mathrm{~h}$; and iii) propofol + chemically-induced hypoxia group, with the cells pretreated with $50 \mu \mathrm{g} / \mathrm{ml}$ propofol for $2 \mathrm{~h}$ and then exposed to chemically-induced hypoxia. After removing the culture medium, cells were washed with PBS and incubated in $10 \mu \mathrm{m}$ DCFH-DA in fresh serum-free medium for 30-40 min in a humidified incubator at $37^{\circ} \mathrm{C}$ with $5 \% \mathrm{CO}_{2}$ in the dark. Labeled cells were analyzed using FlowJo software version 7.6.1 (Tree Star, Inc.). All assays were performed in duplicate.

SOD and malondialdehyde (MDA) detection. Total intracellular expression levels of MDA and SOD in AC16 and HCM cells were detected using commercially available kits. Cells were divided into three groups, seeded at $1 \times 10^{6}$ cells/well and the following groups were analyzed: i) Control group, chemically induced hypoxia group; and ii) propofol + chemically induced hypoxia group. To detect MDA and SOD, the supernatants were removed and cells were lysed in $1 \mathrm{ml}$ of cold cell lysis buffer, and then cells were crushed for $30 \mathrm{sec}$ after $5 \mathrm{~min}$. The lysis and further processing were repeated four times. Lysed supernatants were collected by centrifugation at $12,000 \mathrm{x} \mathrm{g}$ for $5 \mathrm{~min}$ at $4^{\circ} \mathrm{C}$. Then, $0.25 \mathrm{ml}$ of each supernatant, $1.5 \mathrm{ml}$ reagent $\mathrm{C}$ solution and $0.3 \mathrm{ml}$ reagent D were mixed (Micro-MDA Assay Reagent kit; cat. no. KGT003; Nanjing KeyGen Biotech Co., Ltd.) according to the manufacturer's protocol, boiled at $95^{\circ} \mathrm{C}$ for $40 \mathrm{~min}$ and then cooled in ice water for $10 \mathrm{~min}$. After centrifugation at $3,000 \mathrm{x} \mathrm{g}$ for $15 \mathrm{~min}$ at $4^{\circ} \mathrm{C}$, absorbance values were detected at $532 \mathrm{~nm}$ using a microplate reader. Cell lysis samples were mixed with the reagents of the Superoxide dismutase (SOD) assay kit (cat. no. KGT00150; Nanjing KeyGen Biotech Co.,Ltd.) according to the manufacturer's instructions. Then, samples were incubated at room temperature for $10 \mathrm{~min}$ and the absorbance was detected at $550 \mathrm{~nm}$ using a microplate reader. The relative activity levels of SOD (U/ml) were calculated using the formula recommended by the supplier of the kit, and expressed according to absorbance levels. MDA and SOD concentrations were determined based on the constructed standard curve and are expressed as nmol/(mg total protein). All assays were performed in duplicate.

Western blot analysis. Western blotting was used to evaluate the activation of the signaling pathways. Total proteins were extracted from cells that underwent different treatments using ice-cold RIPA lysis buffer (Beyotime Institute of Biotechnology) with a protease inhibitor cocktail (Roche Applied Science), and total protein concentration in every sample was determined using a BCA Protein Assay kit (Beyotime Institute of Biotechnology). Then, $40 \mu \mathrm{g}$ of total protein solution for each sample was separated by 

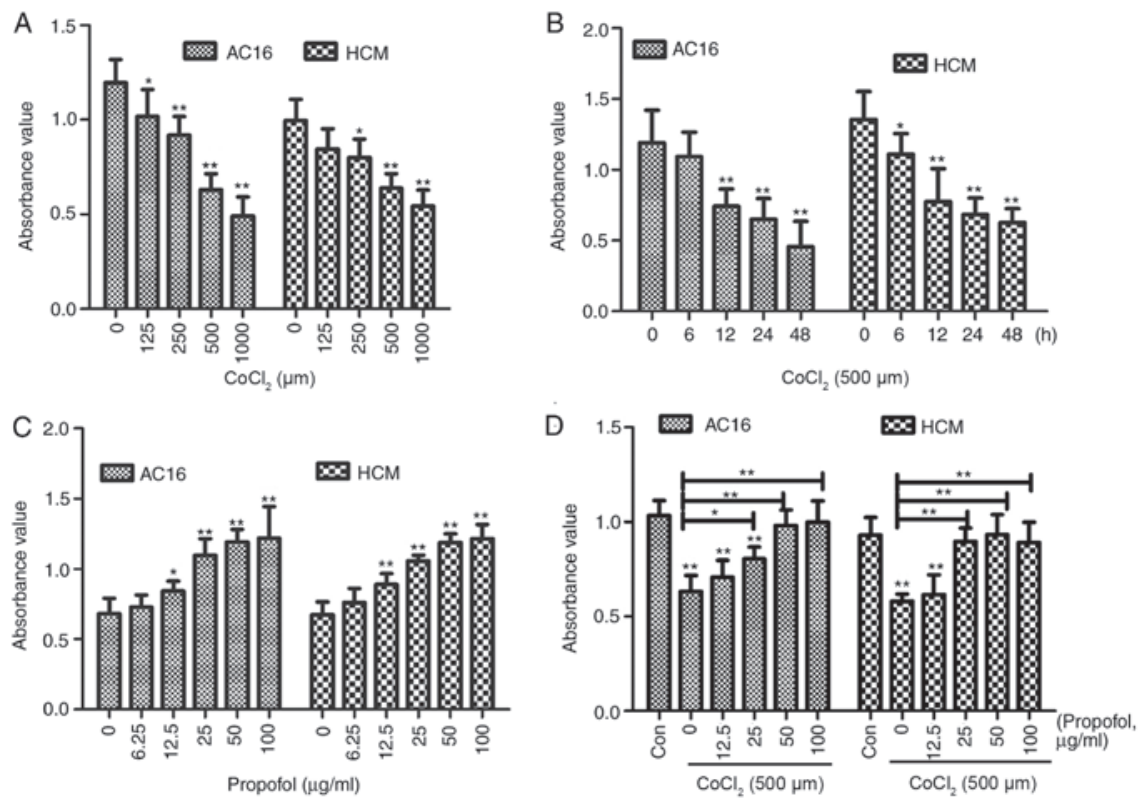

Figure 1. Effects of $\mathrm{CoCl}_{2}$ and propofol on the viability of AC16 and $\mathrm{HCM}$ cardiomyocytes. (A) Treatment of AC16 and $\mathrm{HCM}_{\text {cells with different } \mathrm{CoCl}}$ concentrations for $12 \mathrm{~h}$. (B) Treatment of AC16 and $\mathrm{HCM}$ cells with $500 \mu \mathrm{m} \mathrm{CoCl}_{2}$ for $0,6,12,24$ and $48 \mathrm{~h}$. (C) Cell viability following treatment with different propofol concentrations. (D) Effects of propofol on the viability of cells treated with $\mathrm{CoCl}_{2}$. Data are presented as the mean \pm standard deviation from three independent experiments. ${ }^{~} \mathrm{P}<0.05,{ }^{* *} \mathrm{P}<0.01$. $\mathrm{CoCl}_{2}$, cobalt chloride; Con, control.

$12 \%$ SDS-PAGE and transferred onto PVDF membrane (Bio-Rad Laboratories, Inc.). The membranes were incubated with primary antibodies against JNK1 (1:1,000; cat. no. sc-137018; Santa Cruz Biotechnology, Inc.), phosphorylated (p-)JNK (1:1,000; cat. no. sc-6254; Santa Cruz Biotechnology, Inc.), p38 (1:1,000; cat. no. 8690; Cell Signaling Technology, Inc.), p-p38 (1:1,000; cat. no. 4511; Cell Signaling Technology, Inc.) and GAPDH (1:2,000; cat. no. 5174; Cell Signaling Technology, Inc.) at $4^{\circ} \mathrm{C}$ overnight. Then, the membrane was incubated with a horseradish peroxidase-conjugated secondary antibody (goat anti-mouse IgG $(\mathrm{H}+\mathrm{L})$-horseradish peroxidase (HRP) conjugate; 1:5,000; A16072SAMPLE; Thermo Fisher Scientific,Inc.; Goat anti-Rabbit IgG (H+L) Secondary Antibody-HRP; 1:5,000; Thermo Fisher Scientific, Inc.) at room temperature for $1 \mathrm{~h}$. Protein bands were detected using the enhanced chemiluminescent (ECL) western blotting detection kit (cat. no. E411-03, Vazyme Biotech Co., Ltd.) and the intensity of each western blot band was quantified using Quantity One 1-D Analysis software v4.5 (Bio-Rad Laboratories, Inc.). All experiments were performed in triplicate.

Statistical analysis. Data are presented as mean \pm SD and were analyzed using one-way ANOVA followed by Tukey's test. All statistical analyses were performed using GraphPad Prism 4.00 (GraphPad Software, Inc.). $\mathrm{P}<0.05$ was considered to indicate a statistically significant difference.

\section{Results}

Propofol increases cardiomyocyte viability and inhibits $\mathrm{CoCl}_{2}$-induced cytotoxicity. CCK-8 assay results suggested that cell viability significantly decreased following a 12-h incubation with increasing concentrations of $\mathrm{CoCl}_{2}(0,125,250,500$ or $1,000 \mu \mathrm{m} ;$ Fig. 1A) and incubation with $500 \mu \mathrm{m} \mathrm{CoCl}_{2}$ for different periods $(0,6,12,24$ and 48 h; Fig. 1B). AC16 and HCM cell viability in the chemically induced hypoxia group was shown to decrease to $62.30 \%(0.7419 / 1.1909)$ and $57.13 \%$ (0.7739/1.3546), respectively, compared with the control groups following treatment with $500 \mu \mathrm{m} \mathrm{CoCl}$ for $12 \mathrm{~h}(\mathrm{P}<0.01)$. Therefore, these conditions were selected for further experiments.

To determine the effects of propofol and ropivacaine pretreatment on cardiomyocyte viability, the viability of AC16 and HCM cells treated with propofol or ropivacaine at different concentrations was determined using the CCK-8 assay. The present results suggested that propofol significantly increased cell viability under normal culture conditions in a dose-dependent manner (Fig. 1C). The present results indicated that propofol could reverse the decreased viability of $\mathrm{AC} 16$ and $\mathrm{HCM}$ cells in a dose-dependent manner when combined with $\mathrm{CoCl}_{2}$ treatment. Moreover, the protective effects of propofol against $\mathrm{CoCl}_{2}$ hypoxiainduced injury were identified to be the highest at $50 \mu \mathrm{g} / \mathrm{ml}$ propofol (Fig. 1D; P $<0.01$ ). Compared with the viability observed following the application of propofol, combined propofol and ropivacaine treatment did not increase the viability of cells (Figs. S1 and S2). In addition, regardless of whether the conditions were normoxic or hypoxic, ropivacaine did not affect the viability of AC16 and HCM cells (Fig. S3). Therefore, propofol was selected for further investigation.

Propofol inhibits activation of the JNK signaling pathways in ACl6 and HCM cells exposed to $\mathrm{CoCl}_{2}$. In order to identify the signaling pathways involved in the anti-apoptotic functions of propofol, the present study investigated the activation of the NF- $\mathrm{KB}$ and mitogen-activated protein kinase (MAPK) signaling pathways. These pathways are reported to be the key signal transduction pathways involved in $\mathrm{CoCl}_{2}$-induced apoptosis in BV2 and HK2 cells (18). However, in the present study, propofol did not affect the phosphorylation of p65 subunit, P38, ERKs and JNK in either AC16 or HCM cells (Fig. S4). The present study also investigated the signaling pathways that may underlie the identified propofol effects. AC16 and HCM cells were pre-incubated 
A

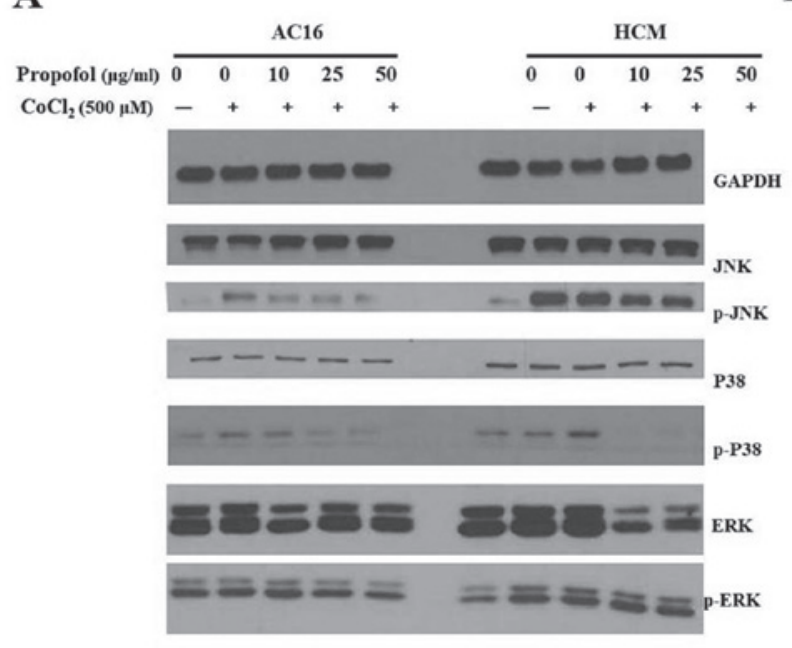

B
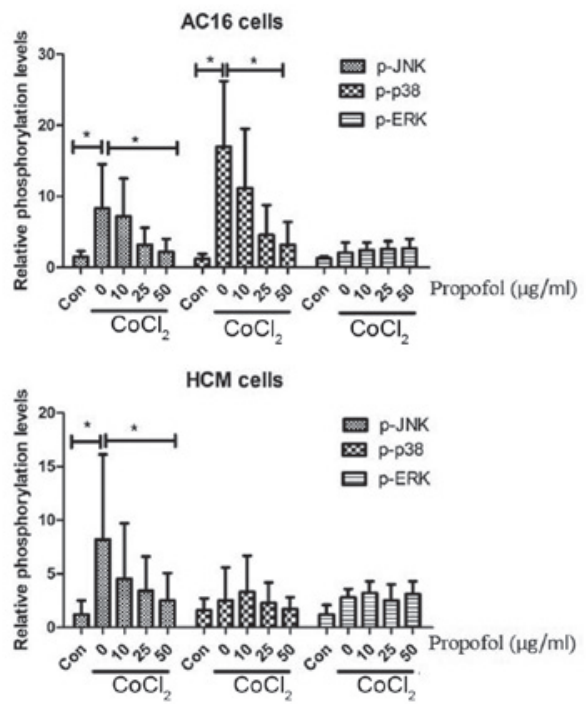

Figure 2. Inhibitory effects of propofol on $\mathrm{CoCl}_{2}$-induced activation of the JNK/MAPK signaling pathways. AC16 and HCM cells were pre-incubated with propofol at different concentrations and then treated with $500 \mu \mathrm{m} \mathrm{CoCl}_{2}$. (A) Western blot analyses of p-P38 and p-JNK in propofol and CoCl ${ }_{2}$-treated $\mathrm{ACl} 16$ and HCM cells. (B) The ratio between the phosphorylated and total protein for JNK, P38 and ERK. Cells treated with different concentrations of propofol and $\mathrm{CoCl}_{2} .{ }^{*} \mathrm{P}<0.05$. $\mathrm{CoCl}_{2}$, cobalt chloride; p-, phosphorylated; Con, control.

A
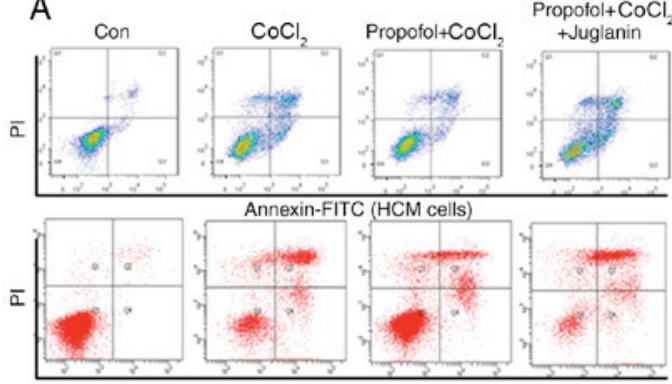

Annexin-FITC (AC16 cells)
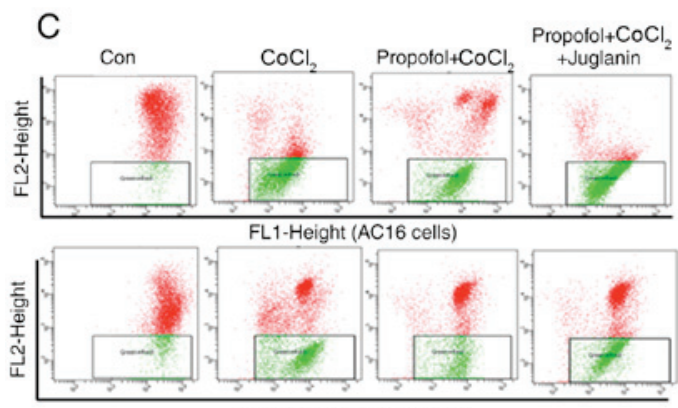

FL1-Height (HCM cells)
B

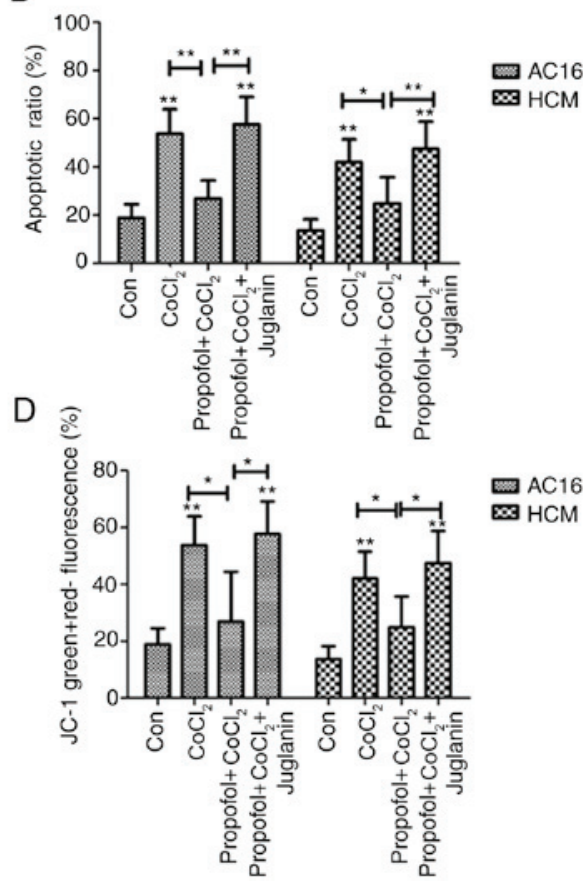

Figure 3. Propofol protects cardiomyocytes against $\mathrm{CoCl}_{2}$-induced apoptosis. Cells were stained with Annexin VFITC/PI and the apoptotic ratio was analyzed using flow cytometry. (A) Representative analysis of the apoptotic ratio of AC16 and HCM cells. (B) Quantification of the flow cytometry results. (C) Mitochondrial membrane potential was investigated using JC-1 staining and flow cytometry analyses. Representative flow cytometry analyses of AC16 and HCM cells. (D) Quantification of the flow cytometry analyses results. Each experiment was repeated $\geq 3$ times. Data are presented as the mean \pm SD. $P<0.05$, ${ }^{* *} \mathrm{P}<0.01$. PI, propidium iodide; $\mathrm{CoCl}_{2}$, cobalt chloride; Con, control.

with propofol at different concentrations and treated with $\mathrm{CoCl}_{2}$. $\mathrm{CoCl}_{2}$ was identified to promote the phosphorylation of JNK and P38 in AC16 cells, and the phosphorylation of JNK in HCM cells following $2 \mathrm{~h}$ treatment, but these effects were significantly inhibited by propofol treatment (Fig. 2). $\mathrm{CoCl}_{2}$ did not increase the phosphorylation of P38 in HCM cells, which may be caused by heterogeneity between cell types. The present results indicated that JNK and p38, but not ERK signaling, represented the main components of the apoptotic pathways contributing to $\mathrm{CoCl}_{2}$-induced apoptosis of AC16 or HCM cells.

Propofol protects against $\mathrm{CoCl}_{2}$-induced cardiac cell apoptosis. $\mathrm{CoCl}_{2}$ has been reported to induce apoptosis of rat cardiac H9C2 cells (22). Therefore, the present study used Annexin V/PI staining to investigate the apoptotic ratio of AC16 and HCM cells following different treatments (Fig. 3A). 
A

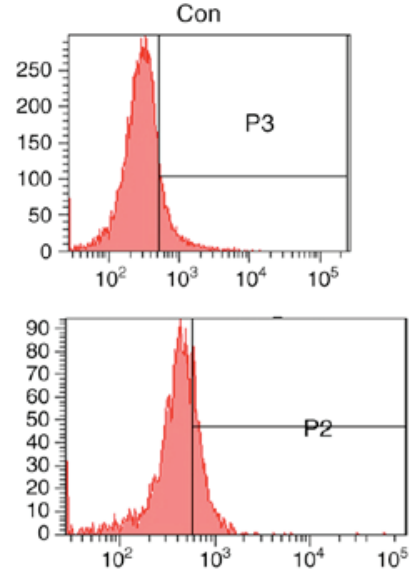

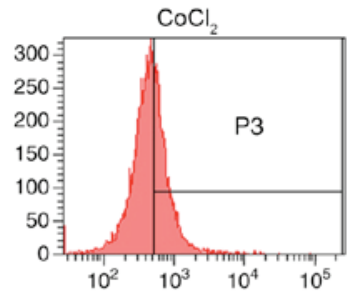

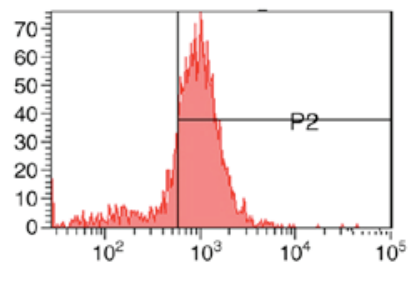

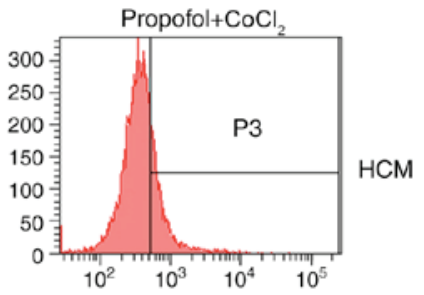

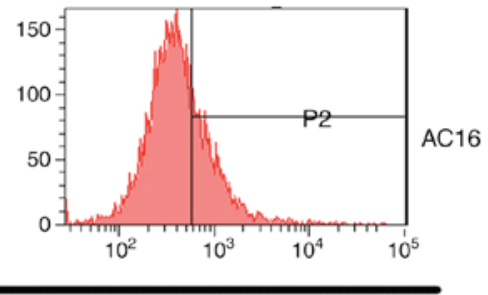

Fluorescence intensity (DCF)

B

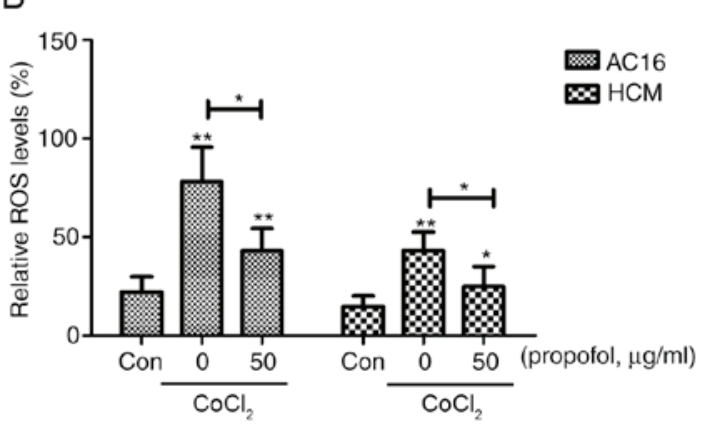

C

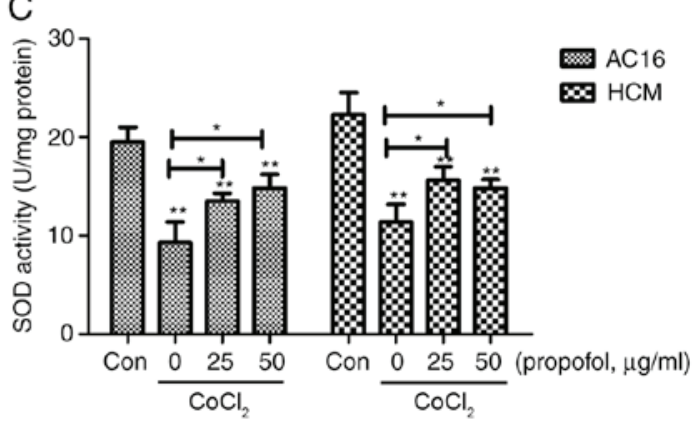

$\mathrm{D}$

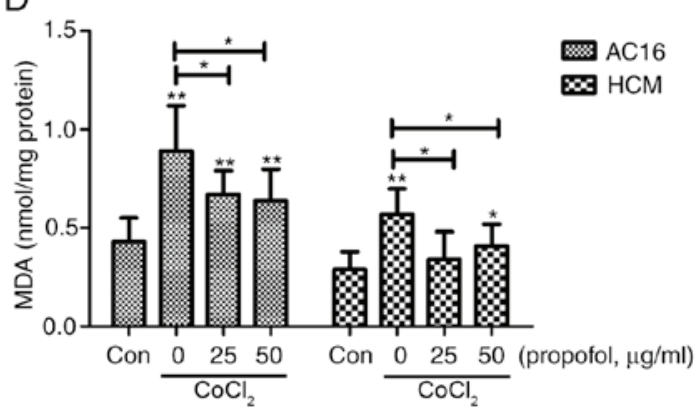

Figure 4. Propofol reduces $\mathrm{CoCl}_{2}$-induced oxidative stress in AC16 and $\mathrm{HCM}$ cells. (A) Representative flow cytometry analyses showing the apoptotic levels of propofol- and $\mathrm{CoCl}_{2}$-treated $\mathrm{AC} 16$ and $\mathrm{HCM}$ cells. (B) Quantification of the flow cytometry results. (C) SOD and (D) MDA expression levels following the treatment with $\mathrm{CoCl}_{2}$ and/or propofol. Data are presented as the mean $\pm \mathrm{SD}$ from three independent experiments. ${ }^{*} \mathrm{P}<0.05,{ }^{* *} \mathrm{P}<0.01$. CoCl ${ }_{2}$, cobalt chloride; Con, control; ROS, reactive oxygen species; SOD, superoxide dismutase; MDA, malondialdehyde.

The ratio of cells in the $500 \mu \mathrm{m} \mathrm{CoCl} \mathrm{Cl}_{2}$-induced hypoxia group was higher compared with the control group $(\mathrm{P}<0.01)$. This ratio was significantly reduced after $2 \mathrm{~h}$ pretreatment with $50 \mu \mathrm{g} / \mathrm{ml}$ propofol prior to the induction of hypoxia. However, the JNK activator juglanin could counteract this reduction and considerably suppressed the anti-apoptotic effects of propofol pretreatment in $\mathrm{CoCl}_{2}$-induced cardiac cells (Fig. 3B).

A hypoxiainduced injury may result in reduced mitochondrial membrane potential (23). Therefore, the present study investigated the effects of propofol on $\Delta \Psi \mathrm{m}$ using JC-1 staining. The present results suggested $50 \mu \mathrm{g} / \mathrm{ml}$ propofol significantly inhibited $\mathrm{CoCl}_{2}$-induced decreases in the $\Delta \Psi \mathrm{m}$ of $\mathrm{AC} 16$ and HCM cells (Fig. 3C and D). Additionally, the present results suggested that juglanin significantly counteracted the recovery effect on $\Delta \Psi \mathrm{m}$ induced by pretreatment with propofol and promoted the reduction of $\Delta \Psi \mathrm{m}$ induced by $\mathrm{CoCl}_{2}(\mathrm{P}<0.05)$.
Propofol reduces $\mathrm{CoCl}_{2}$-induced oxidative stress in $\mathrm{ACl}$ - 16 and HCM cells. Mitochondria are considered the main source of ROS in cells (24). Therefore, the present study investigated the mechanism underlying the propofol-induced mitochondrial protection from oxidative stress. The production of ROS was significantly increased in the $\mathrm{CoCl}_{2}$ group compared with the control group $(\mathrm{P}<0.01)$, and this was shown to be significantly decreased following propofol pretreatment (Fig. 4A and B). Intracellular MDA and supernatant SOD expression levels were also investigated. The present results suggested that the production of MDA was significantly increased in the $\mathrm{CoCl}_{2}$ group compared with the control group, whereas the SOD levels significantly decreased compared with the controls $(\mathrm{P}<0.01$; Fig. 4C and D). These effects of $\mathrm{CoCl}_{2}$ significantly decreased following the application of 25 and $50 \mu \mathrm{g} / \mathrm{ml}$ propofol for $2 \mathrm{~h}$ prior to $\mathrm{CoCl}_{2}$ treatment $(\mathrm{P}<0.05)$. 


\section{Discussion}

Due to its rapid onset of action and rapid recovery profile, propofol is widely used for the initiation and maintenance of general anesthesia, sedation of mechanically ventilated adults, procedural sedation and other similar purposes (25). However, side effects are inevitable and include irregular heart rate, low blood pressure, burning sensation at the site of injection and suppression of breathing (26). Combined application of epidural anesthesia, such as ropivacaine and lidocaine, may reduce the propofol doses required for the induction and maintenance of anesthesia, and further reduce its side effects in clinical practice $(27,28)$. The present study investigated the effects of propofol and/or ropivacaine on cardiomyocytes in vitro under normoxic or $\mathrm{CoCl}_{2}$-induced hypoxic conditions.

In view of the higher detection sensitivity than other tetrazolium salts such as an MTT assay, CCK-8 is widely used for determination of cell viability in cell proliferation and cytotoxicity assays (29). In the present study, although absorbance values were different in control groups of different cells, which may have resulted from different incubation times, cell viability in all assays was accurately assessed by CCK-8.

$\mathrm{CoCl}_{2}$ has been used for mimicking pathophysiological hypoxia/ischemic conditions in vitro, including ROS production, by activating the hypoxic signaling pathway $(23,30)$. The present results suggested that $\mathrm{CoCl}_{2}$ decreased the viability of AC16 and HCM cells in a dose and timedependent manner. To mimic a moderate hypoxic environment, $500 \mu \mathrm{m} \mathrm{CoCl}_{2}$ treatment for $12 \mathrm{~h}$ was selected for further experiments. The present results suggested that this treatment induced cell apoptosis and ROS and MDA production, decreased SOD production and disrupted the integrity of the mitochondrial membrane leading to a reduction of $\Delta \Psi \mathrm{m}$. The present results suggested that $\mathrm{CoCl}_{2}$ treatment may induce the continuous flux of superoxide anions and hydrogen peroxide, inducing oxidative stress in the cells, thus reducing the activity of SOD. Therefore, $\mathrm{CoCl}_{2}$-induced cytotoxicity was suggested to be ROS-dependent.

Propofol was previously reported to protect cells against oxidative stress induced by hydrogen peroxide $(31,32)$, oxygen glucose deprivation (33) and endotoxemia (34), and to inhibit lipid peroxidation in various experimental cell models (35). The present results suggested that propofol significantly increased cell viability under normal culture conditions in a concentration-dependent manner, and the protective effects of propofol pretreatment against $\mathrm{CoCl}_{2}$ hypoxiainduced injury were greatest at a concentration of $50 \mu \mathrm{g} / \mathrm{ml}$. The present results indicated that propofol pretreatment decreased cell apoptosis, prevented impairment of mitochondrial membrane integrity, attenuated the release of ROS and MDA and reversed the $\mathrm{CoCl}_{2}$-induced SOD decrease. The present results suggested that propofol may exert a strong protective effect against oxidative stress-induced injury in cardiomyocytes.

The effects of propofol differ in various cell types due to the activation or inhibition of different signaling pathways (36). However, since ROS-dependent intrinsic apoptosis is generally mediated by MAPK (37), the present study examined the activation of the NF- $\mathrm{KB}$ and $\mathrm{MAPK} / \mathrm{p} 38 / \mathrm{ERK} / \mathrm{JNK}$ signaling pathways, which have been reported to be crucial for $\mathrm{CoCl}_{2}$-induced apoptosis of BV2 (18) and HK2 cells (38).
Following activation of the MAPK signaling cascade ERK plays an anti-apoptotic role, while JNK and p38 exert pro-apoptotic effects during apoptosis. Moreover, the activation of the JNK and p38 signaling pathways was significantly inhibited following exposure to propofol. However, propofol was not shown to affect the phosphorylation of p65, p38, ERK and JNK in $\mathrm{AC} 16$ and $\mathrm{HCM}$ cells. The effect of $\mathrm{CoCl}_{2}$ and propofol treatment was similar between the two cell lines but the magnitude was different, which may be caused by cellular heterogeneity. Therefore, further mechanistic studies are required to fully elucidate the effects of propofol on human cardiomyocytes in order to improve the efficacy and decrease the side effects of the application of this anesthetic during cardiac surgeries.

In conclusion, the present results suggested that pretreatment with propofol may protect human cardiac cells from chemical hypoxiainduced injury via the regulation of the JNK signaling pathways. The present results indicated that propofol may be a promising cardioprotective against a variety of oxidative stress injuries in the heart and may be a suitable drug for the maintenance of anesthesia, especially during cardiac surgery. However, it is not fully understood whether other pathways are involved in these effects; therefore, larger cohort studies are required.

\section{Acknowledgements}

Not applicable.

\section{Funding}

The present study was supported by Nanjing Science and Technology Commission (grant no. 20150325).

\section{Availability of data and materials}

The datasets used and/or analyzed during the current study are available from the corresponding author on reasonable request.

\section{Authors' contributions}

LH participated in the design of experiments, carried out the molecular analysis of cells, interpretation and analysis of data, and helped to draft the manuscript. QZ and YZ were involved in drafting the manuscript and participated in all experiments. YQ has been involved in all aspects of the study, including experimental design, analysis and interpretation of data and writing the manuscript. All authors read and approved the final manuscript.

\section{Ethics approval and consent to participate}

Not applicable.

\section{Patient consent to participate}

Not applicable.

\section{Competing interest}

The authors declare that they have no competing interests. 


\section{References}

1. Hoegberg LC, Bania TC, Lavergne V, Bailey B, Turgeon AF, Thomas SH, Morris M, Miller-Nesbitt A, Mégarbane B, Magder S, et al: Systematic review of the effect of intravenous lipid emulsion therapy for local anesthetic toxicity. Clin Toxicol (Phila) 54: 167-193, 2016.

2. Mather LE: The acute toxicity of local anesthetics. Expert Opin Drug Metab Toxicol 6: 1313-1332, 2010.

3. Butterworth JF IV: Models and mechanisms of local anesthetic cardiac toxicity: A review. Reg Anesth Pain Med 35: 167-176, 2010.

4. Weinberg G: Lipid rescue resuscitation from local anaesthetic cardiac toxicity. Toxicol Rev 25: 139-145, 2006.

5. Gray LD and Morris C: The principles and conduct of anaesthesia for emergency surgery. Anaesthesia 68 (Suppl): S14-S29, 2013.

6. Abubaih A and Weissman C: Anesthesia for patients with concomitant sepsis and cardiac dysfunction. Anesthesiol Clin 34: 761-774, 2016

7. Gottschalk A and Poepping DM: Epidural analgesia in combination with general anesthesia. Anasthesiol Intensivmed Notfallmed Schmerzther 50: 484-493, 2015.

8. Hadimioglu N, Ulugol H, Akbas H, Coskunfirat N, Ertug Z and Dinckan A: Combination of epidural anesthesia and general anesthesia attenuates stress response to renal transplantation surgery. Transplant Proc 44: 2949-2954, 2012.

9. Copeland SE, Ladd LA, Gu XQ and Mather LE: The effects of general anesthesia on the central nervous and cardiovascular system toxicity of local anesthetics. Anesth Analg 106 1429-1439, 2008.

10. Stewart J, Kellett N and Castro D: The central nervous system and cardiovascular effects of levobupivacaine and ropivacaine in healthy volunteers. Anesth Analg 97: 412-416, 2003.

11. Heavner JE, Dryden CF Jr, Sanghani V, Huemer G, Bessire A and Badgwell JM: Severe hypoxia enhances central nervous system and cardiovascular toxicity of bupivacaine in lightly anesthetized pigs. Anesthesiology 77: 142-147, 1992.

12. Rosen MA, Thigpen JW, Shnider SM, Foutz SE, Levinson G and Koike M: Bupivacaine-induced cardiotoxicity in hypoxic and acidotic sheep. Anesth Analg 64: 1089-1096, 1985.

13. Zhang Y, Chen Z, Feng N, Tang, Zhao X, Liu C, Xu H and Zhang M: Protective effect of propofol preconditioning on ischemia-reperfusion injury in human hepatocyte. J Thorac 9: 702-710, 2017.

14. Li Y, Zhong D, Lei L, Jia Y, Zhou H and Yang B: Propofol prevents renal ischemia-reperfusion injury via inhibiting the oxidative stress pathways. Cell Physiol Biochem 37: 14-26, 2015.

15. Tsai YC, Huang CC, Chu LM and Liu YC: Differential influence of propofol on different cell types in terms of the expression of various oxidative stress-related enzymes in an experimental endotoxemia model. Acta Anaesthesiol Taiwan 50: 159-166, 2012.

16. Wang B, Luo T, Chen D and Ansley DM: Propofol reduces apoptosis and up-regulates endothelial nitric oxide synthase protein expression in hydrogen peroxide-stimulated human umbilical vein endothelial cells. Anesth Analg 105: 1027-1033, 2007.

17. Zhang J, Xia Y, Xu Z and Deng X: Propofol suppressed hypoxia/reoxygenation-induced apoptosis in hbvsmc by regulation of the expression of bcl-2, bax, caspase3, kir6.1, and p-JNK. Oxid Med Cell Longev 2016: 1518738, 2016.

18. Lu Y, Gu Y, Ding X, Wang J, Chen J and Miao C: Intracellular $\mathrm{Ca} 2+$ homeostasis and JAK1/STAT3 pathway are involved in the protective effect ofpropofol on BV2 microglia against hypoxia-induced inflammation and apoptosis. PLoS One 12: e0178098, 2017.

19. Ou W, Lv J, Zou X, Yao Y, Wu J, Yang J, Wang Z and Ma Y: Propofol inhibits hepatocellular carcinoma growth and invasion through the HMGA2-mediated Wnt/ $\beta$-catenin pathway. Exp Ther Med 13: 2501-2506, 2017.

20. Wang S, Liang S, Zhao X, He Y and Qi Y: Propofol inhibits cell proliferation and invasion in rheumatoid arthritis fibroblast-like synoviocytes via the nuclear factor- $\kappa \mathrm{B}$ pathway. Am J Transl Res 9: 2429-2436, 2017.

21. Li Q, Qi X and Jia W: 3,3',5-triiodothyroxine inhibits apoptosis and oxidative stress by the PKM2/PKM1 ratio during oxygen-glucose deprivation/reperfusion $\mathrm{AC} 16$ and $\mathrm{HCM}-\mathrm{a}$ cells T3 inhibits apoptosis and oxidative stress by PKM2/PKM1 ratio. Biochem Biophys Res Commun 475: 51-56, 2016.
22. Mao SY, Meng XY, Xu ZW, Zhang WC, Jin XH, Chen X, Zhou X, Li YM and Xu RC: The role of ZFP580, a novel zinc finger protein, in TGF-mediated cytoprotection against chemical hypoxia induced apoptosis in H9c2 cardiac myocytes. Mol Med Rep 15: 2154-2162, 2017.

23. Solaini G, Baracca A, Lenaz G and Sgarbi G: Hypoxia and mitochondrial oxidative metabolism. Biochim Biophys Acta 1797: 1171-1177, 2010.

24. Pascual-Ahuir A, Manzanares-Estreder S and Proft M: Proand antioxidant functions of the peroxisome-mitochondria connection and its impact on aging and disease. Oxid Med Cell Longev 2017: 9860841, 2017.

25. Feng AY, Kaye AD, Kaye RJ, Belani K and Urman RD: Novel propofol derivatives and implications for anesthesia practice. J Anaesthesiol Clin Pharmacol 33: 9-15, 2017.

26. Keyl C, Schneider A, Dambacher M, Wegenhorst U, Ingenlath M, Gruber M and Bernardi L: Dynamic cardiocirculatory control during propofol anesthesia in mechanically ventilatedpatients. Anesth Analg 91: 1188-1195, 2000.

27. Xiang $\mathrm{Y}$ and $\mathrm{Li} \mathrm{YH}$ : Comparison of $1.5 \%$ lidocaine and $0.5 \%$ ropivacaine epidural anesthesia combined with propofolgeneral anesthesia guided by bispectral index. J Zhejiang Univ Sci B 8: 428-434, 2007.

28. Osaka Y, Inomata S, Tanaka E, Nakamura T, Honda K, Miyabe M, Toyooka $\mathrm{H}$ and Tanaka M: Effect of propofol on ropivacaine metabolism in human liver microsomes. J Anesth 20: 60-63, 2006.

29. Ginouves M, Carme B, Couppie P and Prevot G: Comparison of tetrazolium salt assays for evaluation of drug activity against Leishmania spp. J Clin Microbiol 52: 2131-2138, 2014.

30. Jeon YJ, Kim HS, Song KS, Han HJ, Park SH, Chang W and Lee MY: Protective effect of dieckol against chemical hypoxia-induced cytotoxicity in primary cultured mouse hepatocytes. Drug Chem Toxicol 38: 180-187, 2015.

31. Romuk E, Szczurek W, Nowak P, Skowron M, Prudel B, Hudziec E, Chwalińska E1 and Birkner E: Effects of propofol on oxidative stress parameters in selected parts of the brain in a rat model of parkinson disease. Postepy Hig Med Dosw (Online) 70: 1441-1450, 2016.

32. Chen XH, Zhou X, Yang XY, Zhou ZB, Lu DH, Tang Y, Ling ZM, Zhou LH and Feng X: Propofol protects against $\mathrm{H}_{2} \mathrm{O}_{2}$-induced oxidative injury in differentiated pc12 cells via inhibition of $\mathrm{Ca}(2+)$-Dependent NADPH oxidase. Cell Mol Neurobiol 36: 541-551, 2016.

33. Wang Z, Yang P and Qi Y: Role of microRNA-134 in the neuroprotective effects of propofol against oxygen-glucosedeprivation and related mechanisms. Int J Clin Exp Med 8: 20617-206123, 2015.

34. Gokcinar D, Ergin V, Cumaoglu A, Menevse A and Aricioglu A: Effects of ketamine, propofol, and ketofol on proinflammatory cytokines and markers of oxidative stress in a rat model of endotoxemia-induced acute lung injury. Acta Biochim Pol 60: 451-456, 2013.

35. Eriksson O, Pollesello P and Saris NE: Inhibition of lipid peroxidation in isolated rat liver mitochondria by the general anaesthetic propofol. Biochem Pharmacol 44: 391-393, 1992.

36. Jiang S, Liu Y, Huang L, Zhang F and Kang R: Effects of propofol on cancer development and chemotherapy: Potential mechanisms. Eur J Pharmacol 831: 46-51, 2018.

37. Jiang Z, Song F, Li Y, Xue D, Zhao N, Zhang J, Deng G, Li M, Liu X and Wang Y: Capsular polysaccharide of mycoplasma ovipneumoniae induces sheep airway epithelial cell apoptosis via Ros-dependent JNK/P38 MAPK pathways. Oxid Med Cell Longev 2017: 6175841, 2017.

38. Xiong T, Dong W, Fu H, Li Q, Deng C, Lei X and Guo L: Involvement of the nuclear factor- $\kappa \mathrm{B}$ pathway in the adhesion of neutrophils to renal tubular cells after injury induced by neonatal postasphyxial serum. Mol Cell Biochem 388: 85-94, 2014.

This work is licensed under a Creative Commons Attribution-NonCommercial-NoDerivatives 4.0 International (CC BY-NC-ND 4.0) License. 